Article

\title{
Precious Metals in Automotive Technology: An Unsolvable Depletion Problem?
}

\author{
Ugo Bardi $^{1, *}$ and Stefano Caporali ${ }^{2,3}$
}

1 Dipartimento di Scienze della Terra, Università di Firenze, Via G. La Pira 4, 50121 Firenze, Italy

2 Dipartimento di Chimica, Università di Firenze, Via della Lastruccia 3, 50019 Sesto Fiorentino, Italy; E-Mail: stefano.caporali@unifi.it

3 Consorzio Interuniversitario Nazionale per la Scienza e Tecnologia dei Materiali, Via Giusti 9, 50123 Firenze, Italy

* Author to whom correspondence should be addressed; E-Mail: ugo.bardi@unifi.it; Tel.: +39-055-457-3118; Fax: +39-055-457-3120.

Received: 4 November 2013; in revised form: 24 April 2014 / Accepted: 25 April 2014 /

Published: 30 April 2014

\begin{abstract}
Since the second half of the 20th century, various devices have been developed in order to reduce the emissions of harmful substances at the exhaust pipe of combustion engines. In the automotive field, the most diffuse and best known device of this kind is the "three way" catalytic converter for engines using the Otto cycle designed to abate the emissions of carbon monoxide, nitrogen oxides and unburnt hydrocarbons. These catalytic converters can function only by means of precious metals (mainly platinum, rhodium and palladium) which exist in a limited supply in economically exploitable ores. The recent increase in prices of all mineral commodities is already making these converters significantly expensive and it is not impossible that the progressive depletion of precious metals will make them too expensive for the market of private cars. The present paper examines how this potential scarcity could affect the technology of road transportation worldwide. We argue that the supply of precious metals for automotive converters is not at risk in the short term, but that in the future it will not be possible to continue using this technology as a result of increasing prices generated by progressive depletion. Mitigation methods such as reducing the amounts of precious metals in catalysts, or recycling them can help but cannot be considered as a definitive solution. We argue that precious metal scarcity is a critical factor that may determine the future development of road transportation in the world. As the problem is basically unsolvable in the long run, we must
\end{abstract}


explore new technologies for road transportation and we conclude that it is likely that the clean engine of the future will be electric and powered by batteries.

Keywords: platinum; platinum group metals (PGM); automotive; catalytic converter

\section{Introduction}

Road transportation today is mostly based on vehicles powered by internal combustion engines. These engines need fuels which can be easily gasified and which can provide a large amount of energy per unit weight and volume. In practice, all the engines commonly available on the market use hydrocarbons as fuels. In particular, liquid hydrocarbons such as gasoline and diesel fuel are the most commonly used even though, in recent times, gas phase fuels such as methane and liquefied petroleum gas (LPG) have become popular due to their lower cost. The combustion of hydrocarbons in these engines creates a number of polluting substances, including unburnt hydrocarbons, particulate matter, and harmful chemicals such as carbon monoxide $(\mathrm{CO})$ and nitrogen oxides $\left(\mathrm{NO}_{x}\right)$. In engines operating with the Otto cycle and using gasoline as fuel, these chemicals are removed using catalytic converters at the exhaust. These devices can substantially reduce the amount of toxic substances emitted, but they are also expensive because of the need of using platinum group metals (PGM) as active catalytic substrates. On average, an automotive catalytic converter can store $1-3 \times 10^{-3} \mathrm{~kg}$ of platinum and smaller amounts of rhodium and palladium. As a consequence, nowadays, automotive converters use more than half of the world's mineral production of platinum [1]. That raises the question of whether there exist sufficient PGM mineral resources extractable at reasonable prices in order to satisfy the future demand.

This subject has been studied in previous papers and a popularized discussion of the platinum depletion problem was reported by Cohen in 2007 in "The New Scientist" [2]. Several academic papers discussing the issue of PGM supply were published during the past few years, such as by Glaister et al. [3] and Mudd et al. [4], while a paper specifically dedicated to the problem of PGM depletion in view of the needs of the automotive industry was published by Yang in 2009 [5]. In the present paper, we update the previous results and we discuss the issue in view of what appears to be a "production peak" for PGMs observed in recent years. We discuss how the depletion of PGM may affect the world's road transportation system and we arrive to the conclusion that high costs of platinum group metals is a problem destined to get worse with time. That creates a critical problem for a large sector of the world's road transportation system which cannot run without PGM-based catalysts, unless we were to return to unacceptable levels of pollution. This situation is a strong incentive for developing radically different alternatives, in particular battery powered vehicles which are inherently cleaner and appear to suffer from less important depletion problems.

\section{Pollution Removal from Combustion Engines by Means of Catalytic Converters}

Practically all internal combustion engines available on the market today use hydrocarbons as fuels. In principle, non-hydrocarbon fuels, such as pure hydrogen or hydrogen-nitrogen compounds (e.g., 
ammonia), could be also be used, but at present they find no market applications. The combustion of hydrocarbons in internal combustion engines generates mainly water $\left(\mathrm{H}_{2} \mathrm{O}\right)$ and carbon dioxide $\left(\mathrm{CO}_{2}\right)$. Neither is considered a harmful substance even though $\mathrm{CO}_{2}$ is toxic for human beings at very high concentrations [6]. Both water and carbon dioxide are greenhouse gases, but only carbon dioxide creates global warming because, unlike water, it remains in the atmosphere for times of the order of tens of thousands of years [7]. Then, the untreated emissions of an internal combustion engine normally contain substances which are toxic for human beings even at low concentrations. The most important ones are: (1) unburnt hydrocarbons, especially if aromatic, (2) carbon monoxide (CO), (3) nitrogen oxides $\left(\mathrm{NO}_{x}\right)$ and (4) particulate matter, typically in the form of carbon micro and nano-particles (much debate is ongoing about the harmful effect of these particles but it is generally agreed that they are a major health problem [8]). Additives to fuels may also create dangerous materials at the exhaust and, until not long ago, tetra-ethyl lead and ethyl bromide were common additives to gasoline, fortunately today forbidden by law in most (although not all) countries of the world [9].

The removal of carbon dioxide from the exhaust gases of a mobile engine is normally considered impossible, although it can be contemplated in the case of large, stationary engines. However, most of the toxic substances emitted can be strongly reduced in concentration by a combination of suitable operating parameters and catalytic chemical filters at the exhaust. At present, there exist two main approaches in this field. For diesel engines, the "lean" mixture of fuel and air reduces the problem of carbon monoxide and hydrocarbons, so that the main problem is to eliminate particulate matter and nitrogen oxides. The abatement of these pollutants is normally obtained by means of selective catalytic reactions (SCR), that is by a combination of an oxidation catalyst based on cerium oxide (to remove particulate) and by reaction with ammonia to remove nitrogen oxides. Ammonia, in turn, is generated by the injection of urea into the exhaust gas. Exhaust gas recirculation can also be used to reduce $\mathrm{NO}_{x}$ production when starting a cold engine.

For gasoline engines, instead, the problem of particulate matter is less important and the exhaust filter must address the problem of eliminating three different harmful gases: $\mathrm{CO}, \mathrm{NO}_{x}$ and unburnt hydrocarbons. This is accomplished by means of "three way" catalysts based on noble metals (Pt, $\mathrm{Pd}$ and Rh, collectively referred to as "PGM" or "platinum group metals". Of these three metals, rhodium catalyzes reduction while palladium catalyzes oxidation; platinum, is active for both. The task of the catalyst is complex because it must perform several tasks at the same time: oxidize CO and unburnt hydrocarbons, while reducing $\mathrm{NO}_{x}$. In order to optimize the yield of these reactions, the exhaust gas must contain a specific fraction of oxygen. The correct gas composition is obtained by controlling the air/fuel mix by means of oxygen sensors at the exhaust. In general, when in good conditions and operated properly, the converter can remove up to about $90 \%$ of the three gases; as described, for instance, by Kummer [10].

Considerable efforts have been dedicated to developing non-PGM materials that can catalyze these three reactions, but the task has turned out to be very difficult and a practical solution has not been found $[11,12]$. A catalyst which does not use PGMs called "Noxicat"T" has been recently developed, but it is designed mainly for the abatement of $\mathrm{NO}_{x}$ in diesel engines. Other solutions based on oxides such as perovskites [13] and boehmites [14] as catalysts have been proposed but they seem to be far from industrial applications. In the end, the electronic structure of the platinum group metals is unique 
and it generates chemical properties that are not matched by any other element of the periodic table nor by compounds which can remain stable for a long time in the conditions of high temperature of automotive catalytic converters. Therefore, although it is not possible to exclude an unexpected breakthrough, the present situation raises a serious problem of future availability of PGMs in sufficient amounts, as it will be discussed in the next section.

\section{Platinum Group Metals Abundance and Production}

PGMs are rare in the Earth's crust, with typical average abundances of the order of a few parts per billion (ppb) at most. Of the three PGMs used in automotive catalysts, the most abundant is palladium (average $15 \mathrm{ppb}$ ), followed by platinum with $5 \mathrm{ppb}$ and rhodium with about $1 \mathrm{ppb}$ (data from [15]). PGMs are often found in sulphide minerals [16] and are also known to be siderophilic (iron-loving). The latter property accounts for their scarcity on the Earth's crust, since they were efficiently extracted by the metallic Fe-Ni phases in the Earth's core during planetary accretion. PGMs may occur in native form associated with gold, iron, copper and chromium and, due to their high weight and chemical inertness, can also be found in placer deposits. The production of PGMs is concentrated in a few mines: the main ones are the Bushveld igneous complex (South Africa), the sulphide deposits of Norilsk in Russia, placer deposits in the Ural mountains (Russia), the Sudbury mine (Ontario, Canada), the Hartley mine (Zimbabwe), the Still-water complex (Montana, USA), Northern Territory (Australia) and the Zechstein copper deposit in Poland. South Africa produces about $85 \%$ of the total world PGM production has $82 \%$ of the world's resources [17].

According to the United States Geological Survey [18], the total reserves of platinum group metals (PGMs) amount to 66 million tonnes, to be compared to a total combined use of platinum and palladium in 2011 of 400,000 metric tons. Hence, the ratio of reserves to production (R/P, with production assumed to be constant and equal to the present value), is of about 130 years. This result may appear comforting but the question here is not for how long we can produce PGMs in the unlikely hypothesis of constant future production, but how and if it will be possible to keep a sufficiently large production at costs compatible with the needs of road vehicles-i.e., at costs which would not destroy the demand for these elements.

This question is related to a well known effect in economics, that of "diminishing returns". As less and less concentrated ores are exploited, the energy needed for extraction increases. As a consequence, production costs increase and, ultimately, market prices must increase since, obviously, nobody can produce at a loss for a long time. This effect had been described for the first time for mineral resources by William Stanley Jevons in his "The Coal Question" of 1866 [19]. Today, it is known that in many cases, the mineral industry is forced to access resources from lower and lower grade ores, as it has been shown, for instance, for the case of copper in a recent paper by Mudd and Weng [20]. This effect is surely a factor in the observed increasing prices of most mineral resources worldwide (see, e.g., Valero [21]). However, the increasing prices of all mineral commodities are also directly related to the increased prices of fossil fuels which provide most of the energy needed for extraction. As shown by Hall et al. [22], the progressive depletion of fossil fuels causes a reduction of the energy return on energy invested (EROI) which in turn generates a rise in prices as the result of the decreasing economic returns on extraction. In the case of platinum group metals, all these factors are at play and 
Mudd [4] clearly shows that the industry is progressively forced to exploit lower grade, more expensive PGE metal ores.

In Figure 1, we can observe how the production of both platinum and palladium appear to have peaked in 2006, maintaining a plateau at lower levels afterward. "Peaking" is a phenomenon which appears to be of general validity in mineral extraction and occurs as a result of growing extractive costs. However, it is not easy to predict when a certain mineral resource will peak. The standard method to analyze peaking trends is often termed the "Hubbert method" (so called because of the name of the author who first mentioned the concept for the case of crude oil [23]). It is based on an estimate of the amount of resources which are defined as "extractable" and this estimation involves assumptions on the future economy in terms of demand and prices. On the basis of this method, Mudd et al. [4], have estimated that the actual "production peak" for PGMs should not occur before approximately 2050 if the present level of demand is maintained. However, we cannot exclude that a weak economy would depress demand and make the 2006 peak as the ultimate production peak for these metals. In any case, the plateauing of the past few years clearly indicates the strain placed on the industry by a combination of high costs of extraction and high costs of energy. The result is the observed increase in the prices of PGMs. For instance, platinum prices have increased of a factor of about 5 from 1992 to 2012 [24] reaching today a level of about 1500 U.S. dollars per ounce, that is more than 50 dollars per gram. The historical maximum has been in 2008, when platinum reached levels of about 80 dollars per gram (see Figure 1). The other PGMs, palladium and rhodium, have shown similar increases in relative terms.

Figure 1. (A) Pd (red) and Pt (black) monthly average price in U.S. dollars per troy oz and (B) world production in thousands of tons. Data sources $[25,26]$.

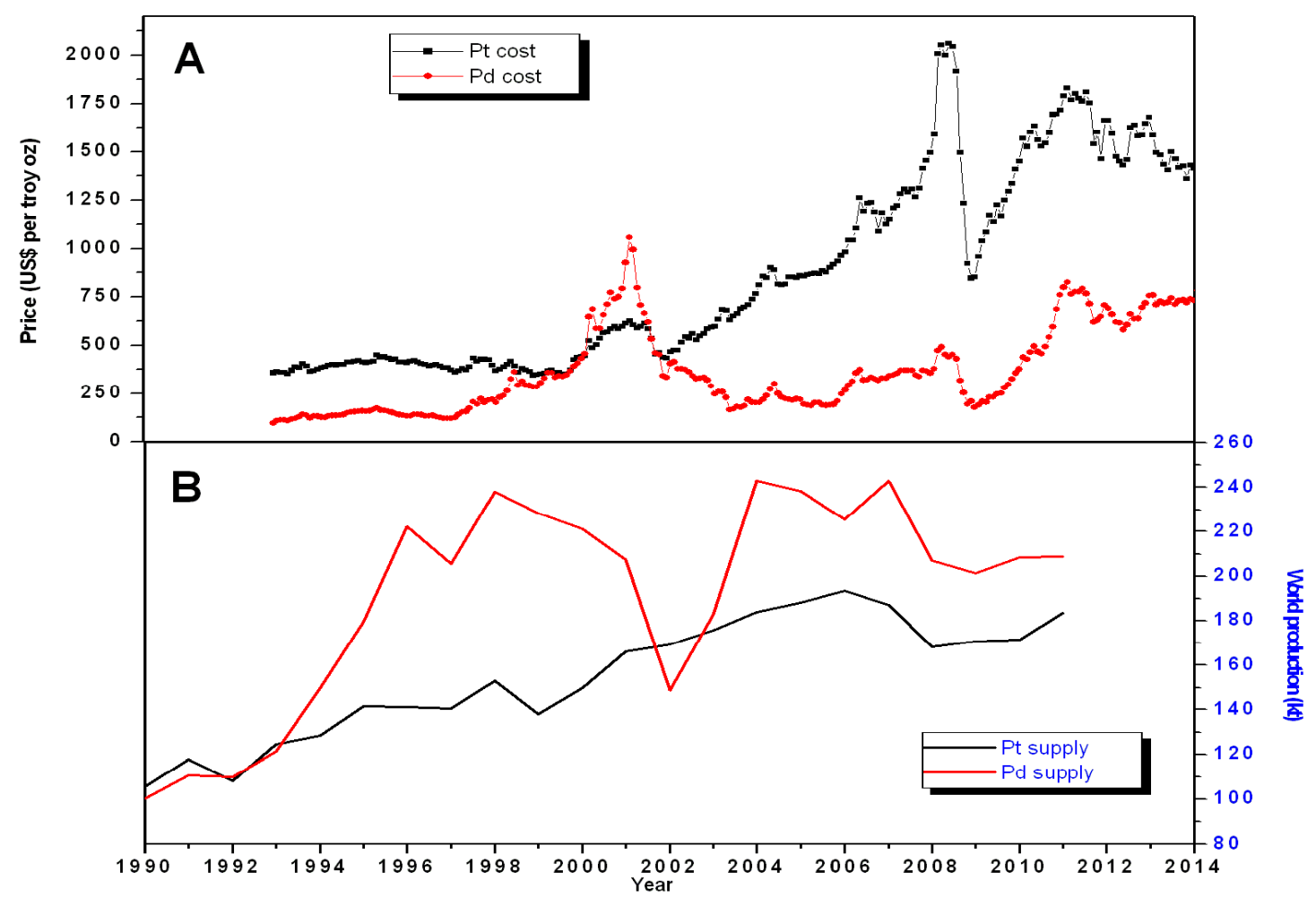


At these levels, the cost of the active metals in a three way catalytic converter can be 200-300 dollars. If the rising trend continues, the cost of the converter may become a major fraction of the cost of small car. We also need to take into account that catalytic converters are not the only technological applications which need PGMs. Fine chemical catalysts, anticancer drugs, as well as ORR (oxygen reduction reactions) are fields of great industrial relevance on which the use of PGMs is considered unavoidable [27].

What can be done to ease the high costs problems that derive from increasing PGM scarcity? As discussed in the previous section, developing non noble metal catalysts appears to be a very difficult option, hence - if we want to maintain the present technology of pollution abatement in combustion engines - we can at least mitigate the problem by (1) reducing the amount of catalyst in the converters and (2) recycling platinum group elements more efficiently.

Reducing the amount of PGMs in catalytic converters - and in particular of the expensive platinum - is possible, but there are limits to this approach. Often, it is possible to attain such a reduction by increasing the surface/volume ratio of the catalytic particles, that is making them smaller. However, below some dimensions, the particles become unstable, may move and coalesce with other particles with an overall loss of catalytic activity, or simply, they can be removed from the substrates and be carried away by the exhaust. It is also possible to vary the ratio of the different metals in the catalyst, for instance partly replacing platinum with palladium, which has a market price about one third lower. This is a route presently explored by catalyst manufacturers but, of course, it doesn't solve the problem at its roots.

Regarding recycling, there exist established procedures to recover platinum and the other noble metals from automotive converters with good efficiency [28]. The concentration of platinum in converters may be as high as $2 \mathrm{~g} / \mathrm{t}$ in the ceramic catalyst brick, of the same order of magnitude as the gold content in primary ores (on average $<10 \mathrm{~g} / \mathrm{t}$ ). However, the end of life recycling rates of platinum from catalytic converters reach a global average of only $50 \%-60 \%$ [29].

This relatively low amount recycled is the result of two factors: one is the loss of noble metals during the life cycle of the catalyst, the other is that not all catalytic converters are actually recycled because cars may end their life in remote areas where there are no recycling facilities, or be lost in conditions where the catalyst cannot be conveniently recovered. While the recovery rate of old converters can surely be improved, we face a fundamental problem when considering the PGM loss at the exhaust. In an early study [30] the loss (or "attrition") of noble metals during operation has been estimated as $6 \%$ over $80,000 \mathrm{~km}$ of operation of the car. These metals are potentially dangerous pollutants and have generated serious concerns regarding their effects on the environment [31] and on human health $[32,33]$. Apart from this, these metals are dispersed in the environment at very low concentrations and are lost forever for all practical purposes. For this reason, recycling alone cannot solve the PGM depletion problem.

\section{Consequences of PGM Scarcity: Moving to Electric Transportation}

Given the inherent limitations of the previously discussed solutions for the limited availability of PGMs, it appears clear that the scarcity of platinum group metals is a critical factor in the future of road transportation. What alternatives can be conceived to solve the problem? As a first possibility, we 
may think of fuels not based on hydrocarbons: pure hydrogen $\left(\mathrm{H}_{2}\right)$ and compounds of hydrogen and nitrogen (such as ammonia, $\mathrm{NH}_{3}$ ) can power internal combustion engines and the exhaust is not expected to contain unburnt hydrocarbons, particulate, or carbon monoxide. It may still contain nitrogen oxides, but these can be abated with catalysts which do not contain PGMs. The problem with this approach, however, is that these fuels cannot simply substitute presently used hydrocarbon fuels: shifting to hydrogen or ammonia would require completely different facilities for fuel distribution and transportation. Moreover, in the end, these fuels are still anchored to the inefficient internal combustion engine which is a major disadvantage in a period of high energy costs as the one in which we are living.

A more drastic and effective idea to solve the PGM problem would be move to a completely different category of engines: electric motors. These motors are lighter, more durable, more efficient and emitting no pollutants. Electric vehicles are already well known and diffused all over the world, although they remain, still today, a minority component of the transportation system. Their diffusion has been limited so far by a series of factors, including the poor performance in terms of power stored per unit weight of the current generation of batteries based on lead. The weight and the volume of batteries strongly limits the range of electric vehicles, except for the case of electric trains or other vehicles powered by aerial wires. As this limited range is considered to be a critical defect of road based electric vehicle, much research has been performed on ways to power electric motors by means of on-board power sources which could provide a significantly higher energy density than lead batteries. A much discussed possibility in this field is to use fuel cells operated using hydrogen as fuel. Fuel cells are efficient converters of the chemical energy stored in hydrogen, able to transform it directly into electrical energy. Because of this factor, fuel cell powered road vehicles can attain an acceptable range by avoiding the need of an inefficient thermal engine. Unfortunately, this approach raises an even worse platinum depletion problem than that encountered with exhaust catalysts. Low temperature fuel cells, usually using proton exchange membranes as electrolyte, need about $1-3 \times 10^{-3} \mathrm{~kg}$ of platinum per $\mathrm{kW}$ of engine power as catalyst at the electrodes. Replacing the present world fleet of road vehicles with this kind of technology would simply not be possible with the limited platinum reserves available [34]. The industry is making a considerable effort in order to reduce the amount of platinum used in fuel cells, but it does not appear possible to eliminate it completely.

So, a better idea to provide power for road vehicles may be based on the new generation of lightweight batteries for automotive use. In the past, several new electrochemical systems were proposed and tested, such as nickel-cadmium, or nickel-metal hydride. However, at present the main effort in this field is directed toward batteries based on lithium compounds, which provide the best available values of energy density. The range of a road vehicle powered by lithium batteries is still lower than that obtained by traditional thermal engines, but it is often perceived acceptable by customers. The problem with lithium is that it may also suffer from depletion problems and this fact has generated a lively debate on the subject [35-39].

On this point, we remark that there are three main types of lithium sources: brines, minerals (e.g., pegmatites), and seawater. Brines formed by evaporation are commonly found in salt flats, such as those located in South America, China, and Tibet. Among these salt flats, the Salar de Atacama in Chile is at present the world's largest currently exploited lithium deposit, producing almost $40 \%$ of world lithium. At the current production rate (37,000 t per year), the known lithium reserves 
(13 million tonnes) [18] would last for more than 300 years. If we could exploit all the land-based estimated resources then we would have about a millennium's supply, even without considering the other possible land sources. About seawater, lithium is one of the few minerals whose concentration is sufficiently high that extraction from the sea is an economically conceivable task [40], even though it is not industrially performed today.

However, just as it was discussed for PGMs, simply listing theoretically available resources is not a good way to understand how depletion will affect extraction costs and, hence, market prices. A detailed comparison of the relative depletion trends for PGMs and lithium is outside the scope of the present paper. However, we wish to remark that: (1) Unlike platinum and other PGMs, lithium production, so far, has shown no production peaks. (2) Lithium prices have increased during the past few years, following the general trend of mineral commodities, however-unlike the case of PGMs - the pure cost of lithium is still a negligible fraction of the total cost of an electric car. (3) Lithium recycling does not suffer of the dispersion problem that strongly limits the fraction of the PGMs which can be recycled from a catalytic converter. At present, lithium prices are still so low that recycling is not normally performed, but in the future that will be certainly possible. (4) Most of the negative views of lithium future availability, e.g., those expressed by Tahil [34] are the result of the assumption of a continued growth in the number of road vehicles for the foreseeable future. This assumption looks unrealistic in the present situation of economic constraints. The world sales of cars are still weakly increasing [41] but have stalled and are going down in many countries. This situation appears to be leading to a stasis and perhaps a contraction in the number of road vehicles that society will be able to afford in the future and that will surely ease the depletion problem with lithium, especially considering that, unlike the case of PGM, a very high recycling rate is possible with lithium batteries.

As a final note, we need to consider also that a radical shift to electric vehicles would also generate the problem of obtaining sufficient electric energy. This subject is beyond the scope of the present paper, but it is a very general problem that involves the transition from a fossil fuel based economy to a renewable (or nuclear) based one. In general terms, the transition is ongoing $[42,43]$ and it is involving a shift from chemical energy obtained from fossil carbon to electric power directly obtained from non-carbon fueled sources. This transition is obviously favoring applications which can directly use this electric power, such as electric vehicles.

So, at least for those applications which do not demand long range transportation, the substitution of internal combustion engines with battery powered electric motors would greatly reduce pollution and lengthen the life span of the presently available mineral resources of platinum group metals which could therefore be saved for other purposes in catalysis as well as in other fields of the chemical industry.

\section{Conclusions}

The peaking observed in the production curve for platinum group metals indicates that the mining industry is already under heavy strain in maintaining a sufficient supply of PGMs at costs compatible with those of road transportation vehicles. This is a critical problem for the whole world's transportation system and it is not too early to start developing new technologies for road transportation which do not involve the use of extremely rare and precious materials where, even in the short term, supply disruption and price spikes could threaten the whole system. In the long run, we 
argue that the only definitive solution for the PGM depletion problem will be to replace vehicles powered by fossil hydrocarbons by battery powered electric vehicles.

\section{Acknowledgments}

The authors would like to thank the Club of Rome for providing a grant that made this study possible within the production of the 33rd report to the Club of Rome titled "Extracted" [44].

\section{Author Contributions}

Both the authors were involved in writing and revising all parts of the manuscript.

\section{Conflicts of Interest}

The authors declare no conflict of interest.

\section{References}

1. Alonso, E.; Field, F.R.; Kirchain, R.E. A Case Study of the Availability of Platinum Group Metals for Electronics Manufacturers. In Proceedings of the 2008 IEEE International Symposium on Electronics and the Environment, San Francisco, CA, USA, 19-22 May 2008.

2. Cohen, D. Earth's Natural Wealth: An Audit. Available online: http://www.sciencearchive.org.au/ nova/newscientist/027ns_005.htm?q=nova/newscientist/027ns_005.htm (accessed on 25 April 2014).

3. Glaister, B.J.; Mudd, G.M. The environmental costs of platinum-PGM mining and sustainability: Is the glass half-full or half-empty? Miner. Eng. 2010, 23, 438-450.

4. Mudd, G.M. Key trends in the resource sustainability of platinum group elements. Ore Geol. Rev. 2012, 46, 106-117.

5. Yang, C.J. An impending platinum crisis and its implications for the future of the automobile. Energy Policy 2009, 37, 1805-1808.

6. Rice, S.A. Human Health Risk Assessment of $\mathrm{CO}_{2}$ Survivors of Acute High Level Exposure and Populations Sensitive to Prolonged Low Level Exposure. In Proceedings of 3rd Annual Conference on Carbon Sequestration, Alexandria, VA, USA, 3-6 May 2004.

7. Archer, D. Fate of fossil fuel $\mathrm{CO}_{2}$ in geologic time. J. Geophys. Res. Ocean. 1978, 110, C09S05, doi:10.1029/2004JC002625.

8. Pope, C.A., III; Burnett, R.T.; Thun, M.J.; Calle, E.E.; Krewski, D.; Ito, K.; Thurston, G.D. Lung cancer, cardiopulmonary mortality, and long-term exposure to fine particulate air pollution. J. Am. Med. Assoc. 2002, 287, 1132-1141.

9. Taylor, R.; Gethin-Damon, Z. Countries Where Leaded Petrol Is possibly still Sold for Road Use as at 17th June 2011. Available online: http://www.lead.org.au/fs/fst27.html (accessed on 10 April 2014).

10. Kummer, J.T. Use of noble metals in automobile exhaust catalysts. J. Phys. Chem. 1986, 90, 4747-4752.

11. Kapteijn, F.; Stegenga, S.; Dekker, N.J.J.; Bijsterbosch, J.W.; Moulijn J.A. Alternatives to noble metal catalyst for automotive exhaust purification. Catal. Today 1993, 16, 273-287. 
12. Fechete, I.; Wang, Y.; Védrine, J.C. The past present and future of heterogeneous catalysis. Catal. Today 2012, 189, 2-27.

13. Qi, G.; Li, W. Pt-free $\mathrm{LaMnO}_{3}$ based lean $\mathrm{NO}_{x}$ trap catalyst. Catal. Today 2012, 184, 72-77.

14. Gálvez, M.E.; Ascaso, S.; Tobías, I.; Moliner, R.; Lázaro, M.J. Catalytic filters for the simultaneous removal of soot and $\mathrm{NO}_{x}$ : Influence of the alumina precursor on monolith washcoating and catalytic activity. Catal. Today 2012, 191, 96-105.

15. Linde, D.R. Section 14, Geophysics, Astronomy, and Acoustics; Abundance of Elements in the Earth's Crust and in the Sea. In CRC Handbook of Chemistry and Physics, 85th ed.; Lide, D.R., Ed.; CRC Press: Boca Raton, FL, USA, 2005.

16. Rankama, K.; Sahama, T.G. Geochemistry; The University of Chicago Press: Chicago, IL, USA, 1952.

17. Rao, C.R.M.; Reddi, G.S. Platinum group metals (PGM); Occurrence, use and recent trends in their determination. Trends Anal. Chem. 2000, 19, 565-586.

18. U.S. Department of the Interior; U.S. Geological Survey. Mineral Commodity Summaries 2012; U.S. Geological Survey: Reston, VA, USA; pp. 120-121. Available online: http://minerals.usgs.gov/ minerals/pubs/mcs/2012/mcs2012.pdf (accessed on 10 April 2014).

19. Jevons, W.S. The Coal Question: An Enquiry Concerning the Progress of the Nation, and the Probable Exhaustion of Our Coal-Mines, 2nd ed.; Macmillan and Co.: London, UK, 1866.

20. Mudd, G.M.; Weng, Z. Base Metals. In Materials for a Sustainable Future; Peter, L., Letcher, T.M., Scott, J.L., Salminen, J., Eds.; Royal Society of Chemistry: London, UK, 2012; pp. 11-55.

21. Valero, A. Mineral Resource Depletion Assessment. In Eco-Efficient Construction and Building Materials; Pacheco-Torgal, F., Cabeza, L., Labrincha J.; De Magalhaes, A., Eds.; Woodhead Publishing: Cambridge, UK, 2014; pp. 13-37.

22. Hall, C.A.S.; Lambert, J.G.; Balogh, S.B. EROI of different fuels and the implications for society. Energy Policy 2014, 64, 141-152.

23. Hubbert, M.K. Nuclear Energy and the Fossil Fuels. Presented at the Spring Meeting of the Southern District, American Petroleum Institute, San Antonio, TX, USA, 7-9 March 1956.

24. Kitco Web Page. Available online: http://www.kitco.com/charts (accessed on 10 April 2014).

25. Platinum Today, Johnson Matthey Market Data Tables. Available online: http://www.platinum.matthey.com/prices/price-charts (accessed on 4 April 2014).

26. U.S. Geological Survey Web Page. Platinum-Group Metals: Statistics and Information. Available online: http://minerals.usgs.gov/minerals/pubs/commodity/platinum/ (accessed on 10 April 2014).

27. Ungvary, F. Transition metals in organic synthesis: Hydroformylation, reduction, and oxidation: Annual survey covering the year 1993. Coord. Chem. Rev. 1995, 141, 371-493.

28. Hagelüken, C. Recycling the platinum group metals: A European perspective. Platinum Metals Rev. 2012, 56, 29-35.

29. Graedel, T.E.; Allwood, J.; Birat, J.-P.; Reck, B.K.; Sibley, S.F.; Sonnemann, G.; Buchert, M.; Hagelüken, C. Recycling Rates of Metals-A Status Report; United Nations Environment Programme: Paris, France, 2011.

30. Hill, R.F.; Mayer, W.J. Radiometric determination of platinum and palladium attrition from automotive catalysts. IEEE Trans. Nucl. Sci. 1977, 24, 2549-2554. 
31. Moldovan, M.; Palacios, M.A.; Gómez, M.M.; Morrison, G.; Rauch, S.; McLeod, C.; Ma, R.; Caroli, S.; Alimonti, A.; Petrucci, F.; Bocca, B.; Schramel, P.; Zischka, M.; Petterson, C.; Wass, U.; Luna, M.; Saenz, J.C.; Santamaria, J. Environmental risk of particulate and soluble platinum group elements released from gasoline and diesel engine catalytic converters. Sci. Total Environ. 2002, 296, 199-208.

32. Caroli, S.; Alimonti, A.; Petrucci, F.; Bocca, B.; Krachler, M.; Forastiere, F.; Sacerdote, M.T.; Mallone, S. Assesment of exposure to platinum-group metals in urban children. Spectrochim. Acta $B$ 2001, 56, 1241-1248.

33. Bocca, B.; Alimonti, A.; Cristaudo, A.; Cristallini, A.; Petrucci, F.; Caroli, S. Monitoring of the exposure to platinum group elements for two Italian population groups through urine analysis. Anal. Chim. Acta 2004, 512, 19-25.

34. Bossel, U. Does a hydrogen economy make sense? Proc. IEEE 2006, 94, 1826-1836.

35. Gruber, P.W.; Medina, P.A.; Keoleian, G.A.; Kesler, S.E.; Everson, M.P.; Wallington, T.J. Global lithium availability. J. Ind. Ecol. 2011, 5, 760-775.

36. Tahil, W. The Trouble with Lithium 2: Under the Microscope; Meridian International Research: Martainville, France, 2008.

37. Yaksic, A; Tilton, J.E. Using the cumulative availability curve to assess the threat of mineral depletion: The case of lithium. Resour. Policy 2009, 34, 185-194.

38. Kushnir, D.; Sandén, B.A. The time dimension and lithium resource constraints for electric vehicles. Resour. Policy. 2012, 37, 93-103.

39. Kesler, S.E.; Gruber, P.W.; Medina, P.A.; Keoleian, G.A.; Everson, M.P.; Wallington, T.J. Global lithium resources: Relative importance of pegmatite, brine and other deposits. Ore Geol. Rev. 2012, 48, 55-69.

40. Bardi, U. Extracting minerals from seawater: An energy analysis. Sustainability 2010, 2, 980-992.

41. Gomes, C. Global Auto Report; Scotiabank Economics: Toronto, ON, Canada, 2014. Available online: http://www.globalstrategicmetalsnl.com/_content/documents/405.pdf (accessed on 10 April 2014).

42. Bardi, U. The grand challenge of the energy transition. Front. Energy Res. 2013, 1, doi:10.3389/fenrg.2013.00002.

43. Jacobson, M.Z.; Delucchi, M.A. Providing all global energy with wind, water, and solar power, Part I: Technologies, energy resources, quantities and areas of infrastructure, and materials. Energy Policy 2011, 39, 1154-1169.

44. Bardi, U. Extracted: How the Quest for Mineral Wealth Is Plundering the Planet; Chelsea Green: Hartford, VT, USA, 2014.

(C) 2014 by the authors; licensee MDPI, Basel, Switzerland. This article is an open access article distributed under the terms and conditions of the Creative Commons Attribution license (http://creativecommons.org/licenses/by/3.0/). 